\title{
Determinants of epidemiologic transition in rural Africa: the role of socioeconomic status and drinking water source
}

\author{
Frouke M. Engelaer ${ }^{a, b, *}$, Jacob J. E. Koopman ${ }^{a, b}$, David van Bodegom ${ }^{a, b}$, Ulrika K. Eriksson ${ }^{b}$ and Rudi G. J. Westendorp ${ }^{a, b}$ \\ aLeyden Academy on Vitality and Ageing, Rijnsburgerweg 10, 2333 AA, Leiden, The Netherlands; ${ }^{b}$ Department of Gerontology \\ and Geriatrics, Leiden University Medical Center, Post Box 9600, 2300 RC, Leiden, The Netherlands \\ *Corresponding author: Tel: +31 71 5240960; Fax: +31 71 5240969; E-mail: engelaer@leydenacademy.nl
}

Received 29 October 2013; revised 10 March 2014; accepted 11 March 2014

\begin{abstract}
Background: Many African countries experience a protracted epidemiologic transition, different from the classical transition in western societies. The factors driving this protracted transition are largely unknown. In northeast Ghana, we studied an ongoing epidemiologic transition and investigated the effects of socioeconomic status and drinking water source on the transition.
\end{abstract}

\begin{abstract}
Methods: During a 9-year period, we followed a cohort of almost 30000 individuals and collected information on mortality and fertility rates. In addition, using the standards set out by the WHO, we obtained the causes of death by verbal autopsy. Individuals were stratified according to their socioeconomic status and the households' use of an improved or unimproved drinking water source.
\end{abstract}

Results: Mortality rates decreased by $-5.0 \%$ annually $(p<0.001)$ and the main cause of death shifted from infectious to non-infectious diseases ( $p=0.014)$. General fertility rates and child-women ratios decreased annually by $-12.7 \%(p<0.001)$ and $-11.9 \%(p<0.001)$, respectively. There was no difference in the decline of mortality and fertility depending on socioeconomic status or drinking water source.

Conclusions: Factors other than socioeconomic status and drinking water source are responsible for the observed declines in mortality and fertility observed during the protracted epidemiologic transition. Identifying the specific determinants of the ongoing transition is of importance, as they could be targeted in order to further improve public health in rural African countries.

Keywords: Drinking water, Epidemiologic transition, Fertility, Ghana, Mortality, Socioeconomic status

\section{Introduction}

The course of epidemiologic transition was first described by Omran in 1971. ${ }^{1}$ According to his model, epidemiologic transition is a process with a decline in mortality, followed by a decline in fertility. The first stage is characterised by pre-transitional patterns of health and disease, with pestilence and famine leading to high and fluctuating mortality together with high fertility. The average life expectancy is about 20 to 40 years. During the second stage, mortality gradually declines as epidemic outbreaks become less frequent. The average life expectancy increases to 30 to 50 years. During the last stage, fertility rates start to decline and mortality is further reduced. Degenerative and man-made diseases prevail and the average life expectancy exceeds 50 years.

It is debated how currently developing countries, including those in rural Africa, experience the epidemiologic transition. ${ }^{2-5}$ Many developing countries have started to experience a decline in mortality, but also in fertility. ${ }^{6,7}$ Contrary to the classical sequential stages described above, these countries suffer from the coexistence of infectious and degenerative diseases, which is denominated as polarisation. ${ }^{3,5,8}$ It has therefore been proposed that we adopt a protracted model for the epidemiologic transition in developing counties, in which the classic stages overlap. ${ }^{1,2,5}$ In addition, factors that have played an essential role in the classical epidemiologic transition, such as improvements in hygiene, access to improved drinking water and socioeconomic status, ${ }^{1}$ have been shown to determine the survival probability in rural Africa. ${ }^{9,10}$ However, it is unclear whether these factors drive the decline in mortality and fertility during the current protracted epidemiologic transition. ${ }^{2,6,7}$

In one of the least developed areas of Ghana, we followed a cohort of almost 30000 inhabitants for a period of 9 years and studied the ongoing epidemiologic transition. During this time period we registered survival and fertility rates and obtained the

(c) The Author 2014. Published by Oxford University Press on behalf of Royal Society of Tropical Medicine and Hygiene. All rights reserved. For permissions, please e-mail: journals.permissions@oup.com. 
causes of death by verbal autopsy. We were then able to investigate the effects of socioeconomic status and drinking water source on the changes in mortality and fertility.

\section{Methods}

\section{Ethics statement}

As the majority of the study participants were unable to read or write, informed consent was obtained orally. A consent form was read out to the participants in their local language, explaining the purpose and procedure of the study. For verbal autopsies, the consent form from the verbal autopsy protocol of the WHO was read out. Consent was given in the form of a thumb print. The whole procedure, including the text of the consent form, was approved by the Ethical Review Committee of the Ghana Health Service, the Medical Ethical Committee of the Leiden University Medical Center in Leiden, the Netherlands and by the local chiefs and elders in the research area.

\section{Research area and study population}

This study was conducted in the Garu-Tempane district in the Upper East region of Ghana. A map of the research area is provided in Figure 1. The Upper East region is one of the least developed areas of Ghana, contrasting sharply with the more urbanised and affluent southern parts of the country. ${ }^{11,12}$ The majority of the population are farmers, whose agricultural practices are performed manually and without proper means of transportation, irrigation and electricity. ${ }^{9,13}$ The local economy partly uses the barter system, in which goods are directly exchanged for other

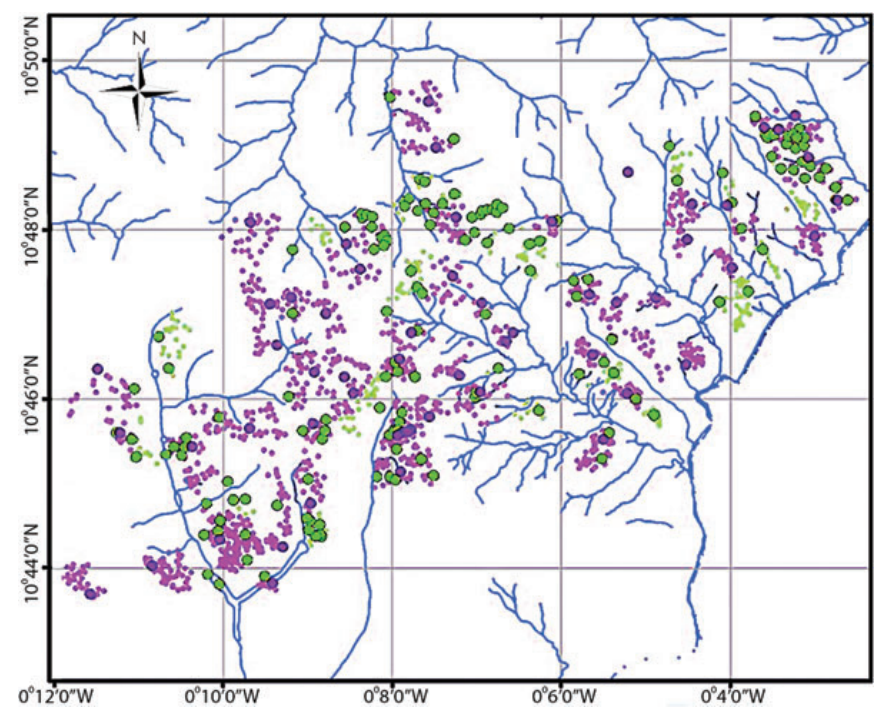

Figure 1. Map of the research area in the Garu-Tempane district in the Upper East region of Ghana. Large purple circles denote improved drinking water sources, while large green circles denote unimproved drinking water sources. Small circles denote households and their colours indicate their primary drinking water source (improved or unimproved). Geographical and hydrological data were provided by the Centre for Remote Sensing and Geographic Information Systems (CERGIS), University of Ghana in Legon, Accra, Ghana. goods or services. ${ }^{11,12}$ Up to half of the population has not received any formal education. ${ }^{11,12}$ Access to medical care in the area is limited, with most people seeking the help of traditional healers. ${ }^{11,12,14}$ Infectious diseases such as malaria, meningitis, typhoid fever and acute respiratory infections are highly endemic and constitute the main causes of death. ${ }^{14-17}$

During the study, we kept a registry of all of the inhabitants of a specified geographic area in the Garu-Tempane district that comprised of about $375 \mathrm{~km}^{2}$ and 32 villages. We visited the research area every year from 2002 to 2011. Annual migration relative to the total study population was estimated to be $2 \%$ into and $1 \%$ out of the research area. ${ }^{18}$

\section{Socioeconomic status}

The socioeconomic status of each household in 2007 was measured using the Demographic and Health Survey (DHS) method. In short, a DHS wealth index was calculated by listing the household property items of most value (e.g. cattle, bicycles, iron roofing), and the value of these items in US\$ was estimated and totalled for each household. For each individual, the socioeconomic status was classified as being either above or below average based on the DHS wealth index of the household in 2007, split by the median. Detailed descriptions of this method have been published previously. ${ }^{9}$

\section{Water source}

The main drinking water source for each household was registered in 2007. From about 1970 onwards, water boreholes were introduced throughout the research area by foreign non-governmental organisations (NGOs). Their introduction was not influenced by the socioeconomic status of surrounding households. A large number of households in the research area also depended on water from open wells and small rivers. Water from boreholes contain less pathogens and is, therefore, a safer source of water compared to water drawn from open wells and rivers, in which the pathogen content is much higher. ${ }^{10}$ In line with the classifications of the WHO, we classified individuals living in 2007 in a household with access to a borehole as having access to an improved water source. Those living in a household with access only to open wells and rivers were classified as having an unimproved water source (Figure 1). ${ }^{19}$

\section{Mortality}

During the 9-year time period, we constructed life tables for each year of follow-up. The population size at the midpoint of each year of follow-up was estimated as the average of the two population sizes registered at the beginning and at the end of the year. During each year of follow-up, mortality rates were calculated as the registered number of deaths divided by the corresponding midyear population. Since only children who were alive were registered and the registry was updated at one-year intervals, mortality was missed for children born and deceased between the two visits. Individuals aged 1 year or less were therefore excluded from the analyses. Mortality rates were standardised to the population's distribution of age and sex in 2003. 


\section{Verbal autopsies}

To obtain causes of death, we performed interviews in 2011 using validated verbal autopsy questionnaires from the $\mathrm{WHO} .{ }^{20-24} \mathrm{We}$ translated the English questionnaires into the two major local languages, Bimoba and Kusaal. To test whether the questionnaires were translated correctly, we performed back-translations into English using independent translators. In cases of discrepancy, the final translation was decided upon after group discussions with native speakers and medical experts. In the research area, it is customary that one relative or caretaker from the same household closely cares for an ill or dying individual. The verbal autopsy interviews were principally performed with these relatives or caretakers of the deceased individuals. For deceased children, the mother of the child was generally interviewed, while for the deceased elderly, it was usually one of the children living in the same household as the deceased individual.

From a total of 1406 deaths, we were able to complete verbal autopsies for 90\% (1263/1406), of which 1253 were aged 1 year and upwards. Verbal autopsy interviews could not be performed in $10 \%$ of cases, mainly due to the absence of an appropriate respondent at the time of the field visit. Following the guidelines of the $\mathrm{WHO},{ }^{23,24}$ two physicians, blinded for each other's assessment, independently assigned causes of death for each verbal autopsy. If the assigned causes of death differed between the first two physicians, a third physician gave an independent assessment, but was not blinded for the assessment of the first two physicians. A cause of death was obtained if at least two of the physicians agreed; otherwise the cause of death was classified as unspecified. The causes of death were coded according to the International Classification of Diseases (ICD) VA-10 coding, as prescribed by the WHO verbal autopsy method. ${ }^{23,24}$

\section{Fertility}

For each year of follow-up, two period measures of fertility were calculated. As the study population is polygamous with one man marrying up to four women, we calculated fertility measures for both men and women. The general fertility rate (GFR) was calculated by dividing the number of births by the number of men or women aged 19 to 44 years. The child-adult ratio (CAR) was calculated by dividing the number of children aged up to 5 years by the number of men or women aged 19 to 49 years.

\section{Statistical analyses}

To determine the factors responsible for absolute mortality over the whole period of follow-up, we used Cox regression with left truncation of the longitudinal individual survival data. Changes in mortality rates over calendar years were determined and tested by Cox regression with calendar year as a covariate. Changes in the relative proportions of causes of death over calendar years were determined and tested by logistic regression, with calendar year as a covariate. Changes in fertility rates over calendar years were determined and tested by Poisson regression, with calendar year as a covariate and robust Huber-White sandwich estimation of variance. The analyses were also performed separately in three age groups representing children, adults and the elderly, and after stratification by sex, socioeconomic status and drinking water source. The analyses were performed in SPSS Statistics 20 (IBM, NY, USA) and Stata/SE 12.1 (StataCorp, College Station, TX, USA).

\section{Results}

The characteristics of the study participants at baseline in 2002 and at the end of follow-up period in 2011 are presented in Table 1. During this time period we registered 29642 individuals from 1719 different households, with a median (interquartile range) individual follow-up of 8 (4-9) person-years. During this time we observed 4069 births and 1406 deaths.

Figure 2 shows the age distributions of the study population at the start of the study in 2002 and at the end in 2011. A major shift can be seen in the constitution of the population, especially in the youngest age groups. In 2002, the group of 0-9 years made up $44.3 \%$ of the total male population and $37.6 \%$ of the total female population. In 2011, this had decreased to $27.1 \%$ and $25.9 \%$, respectively.

The absolute level of mortality over the whole time period was dependent on age, sex, socioeconomic status and water source. Mortality was higher in men $(+41.3 \%$; $p<0.001)$, for those with a socioeconomic status below average $(+30.7 \% ; p<0.001)$, and for those drinking from an unimproved water source $(+21.1 \%$; $p=0.003)$. The effects of sex, socioeconomic status and water source on mortality were mutually independent and did not interact (all $p>0.05$ ). The effects of socioeconomic status and water source on mortality did not differ between the periods of follow-up before and after 2007 (Supplementary Table 1).

Table 2 shows the causes of death during the follow-up period from 2003 to 2011, as registered by verbal autopsy. Both the absolute number of deaths and the prevalence of infectious causes relative to non-infectious causes of death decreased during the period of follow-up.

Figure 3A shows the decline in age-standardised mortality rates, for both men and women, during the follow-up period from 2002 to 2011. Mortality rates declined for men from 1645

Table 1. Characteristics of the study population (2002-2011)

\begin{tabular}{lcc} 
Year & $\begin{array}{l}2002 \\
\mathrm{n}(\%)\end{array}$ & $\begin{array}{l}2011 \\
\mathrm{n}(\%)\end{array}$ \\
\hline $\begin{array}{l}\text { Total number of individuals } \\
\text { Sex }\end{array}$ & 17178 & 24048 \\
$\quad$ Male & $8191(47.7 \%)$ & $11658(48.5 \%)$ \\
$\quad$ Female & $8987(52.3 \%)$ & $12390(51.5 \%)$ \\
Tribe & & \\
Bimoba & $11168(65.0 \%)$ & $15991(66.5 \%)$ \\
$\quad$ Kusasi & $4694(27.3 \%)$ & $6438(26.8 \%)$ \\
$\quad$ Other & $1316(7.7 \%)$ & $1608(6.7 \%)$ \\
Socioeconomic status & $5762(33.5 \%)$ & $8251(34.3 \%)$ \\
$\quad$ Below average & $11088(64.5 \%)$ & $15154(63.0 \%)$ \\
$\quad \begin{array}{l}\text { Above average } \\
\text { Water source } \\
\text { Unimproved }\end{array}$ & $3254(18.9 \%)$ & $4530(18.8 \%)$ \\
Improved & $13913(81.0 \%)$ & $19020(79.1 \%)$ \\
& &
\end{tabular}


to 868 per 100000 person-years, and for women from 1137 to 534 per 100000 person-years. The overall mortality rate declined by $-5.0 \%$ per calendar year $(p<0.001)$. Mortality rates for infectious causes of death declined by $-6.8 \%$ per calendar year $(95 \%$ CI -9.8 to $-3.8 ; p<0.001$ ), while mortality rates for noninfectious causes of death declined by $-3.6 \%$ per calendar year (95\% CI -6.2 to $-0.8 ; p=0.01)$. As shown in Figure $3 \mathrm{~B}$, during the follow-up period, the major cause of death shifted from infectious to non-infectious diseases $(p=0.014)$.

The annual decline in the mortality rate depending on age, sex, socioeconomic status and water source is shown in Table 3. We studied the interaction between these determinants and the annual decline in the mortality rate. There was no difference in

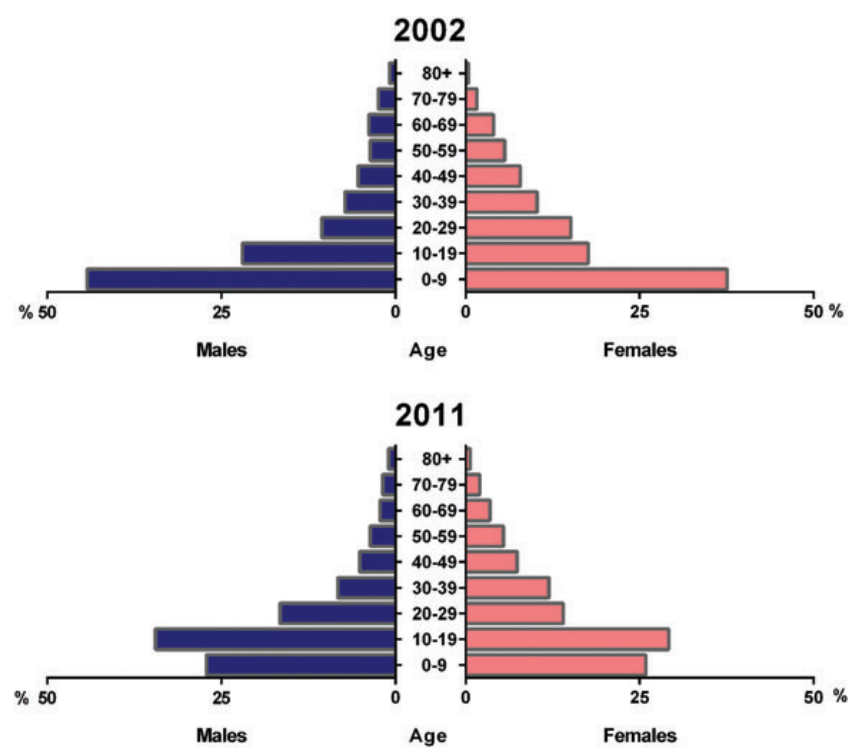

Figure 2. The sex-specific distributions of age groups of individuals in the study population in 2002 (upper pyramid) and 2011 (lower pyramid). the annual mortality rate decline between the age groups, sexes, groups of socioeconomic status or types of water source (all $p>0.05$ ). When studying the interaction between the various determinants and mortality in deaths due to infectious causes or non-infectious causes separately, no interaction was found.

Table 4 shows the annual decline in fertility rates. The GFR is the number of births per 1000 women or men aged 19 to 44 years. The GFR decreased by $-12.7 \%$ per year for women and by $-11.9 \%$ per year for men. The CAR is the number of children aged below 5 years per 1000 women or men, aged 19 to 49 years. The CAR decreased by $-15.0 \%$ per year for women and by $-14.0 \%$ per year for men (both $p<0.001$ ). We observed no differences in these annual declines between the different socioeconomic status groups or types of water sources (all $p>0.05$ ).

The annual decline in fertility rates during the follow-up period from 2002 to 2011, for both men and women, are shown in Figure 4. The decrease in the GFR from 236 to 60 births per 1000 adult men and from 186 to 56 births per 1000 adult women can be seen in Figure 4A. The decrease in the CAR from 1459 to 454 children per 1000 men and from 1138 to 419 children per 1000 women is presented in Figure 4B. During the follow-up period, the trends in fertility of men and women converged. When studying the interaction between sex and fertility decline, there was no interaction between sex and the decline in GFR $(p=0.450)$. However, the interaction between sex and CAR was significant $(p<0.001)$.

\section{Discussion}

This study describes the epidemiologic transition in rural Africa during a period of 9 years. We observed declines in both mortality and fertility. At the same time, the main cause of death changed from infectious diseases to non-infectious diseases. These transitions were not dependent on socioeconomic status or drinking water source.

Table 2. Causes of death during 2003 to 2011 as registered by verbal autopsy

\begin{tabular}{|c|c|c|c|}
\hline Cause of death & $\begin{array}{l}\text { 2003-2005 } \\
\text { n (\%) }\end{array}$ & $\begin{array}{l}\text { 2006-2008 } \\
\text { n (\%) }\end{array}$ & $\begin{array}{l}\text { 2009-2011 } \\
\text { n (\%) }\end{array}$ \\
\hline Infectious and parasitic disorders & $237(51.5 \%)$ & $195(47.4 \%)$ & $169(44.2 \%)$ \\
\hline Neoplasms & $9(2 \%)$ & $10(2 \%)$ & $14(4 \%)$ \\
\hline Nutritional and endocrine disorders & $3(1 \%)$ & $3(1 \%)$ & $0(0 \%)$ \\
\hline Disorders of the circulatory system & $12(2 \%)$ & $9(2 \%)$ & $13(3 \%)$ \\
\hline Respiratory disorders & $2(0.4 \%)$ & $3(1 \%)$ & $4(1 \%)$ \\
\hline Gastrointestinal disorders & $20(4 \%)$ & $21(5 \%)$ & $20(5 \%)$ \\
\hline Renal disorders & $1(0.2 \%)$ & $1(0.2 \%)$ & $0(0 \%)$ \\
\hline Mental and nervous system disorders & $5(1 \%)$ & $3(1 \%)$ & $2(0.5 \%)$ \\
\hline Pregnancy and childbirth-related disorders & $3(1 \%)$ & $9(2 \%)$ & $7(2 \%)$ \\
\hline External causes & $28(6 \%)$ & $36(9 \%)$ & $25(7 \%)$ \\
\hline Other specified causes & $3(1 \%)$ & $0(0 \%)$ & $0(0 \%)$ \\
\hline Unspecified causes & $137(29.8 \%)$ & $121(29.4 \%)$ & $128(33.5 \%)$ \\
\hline Total & $460(100 \%)$ & $411(100 \%)$ & $382(100 \%)$ \\
\hline
\end{tabular}



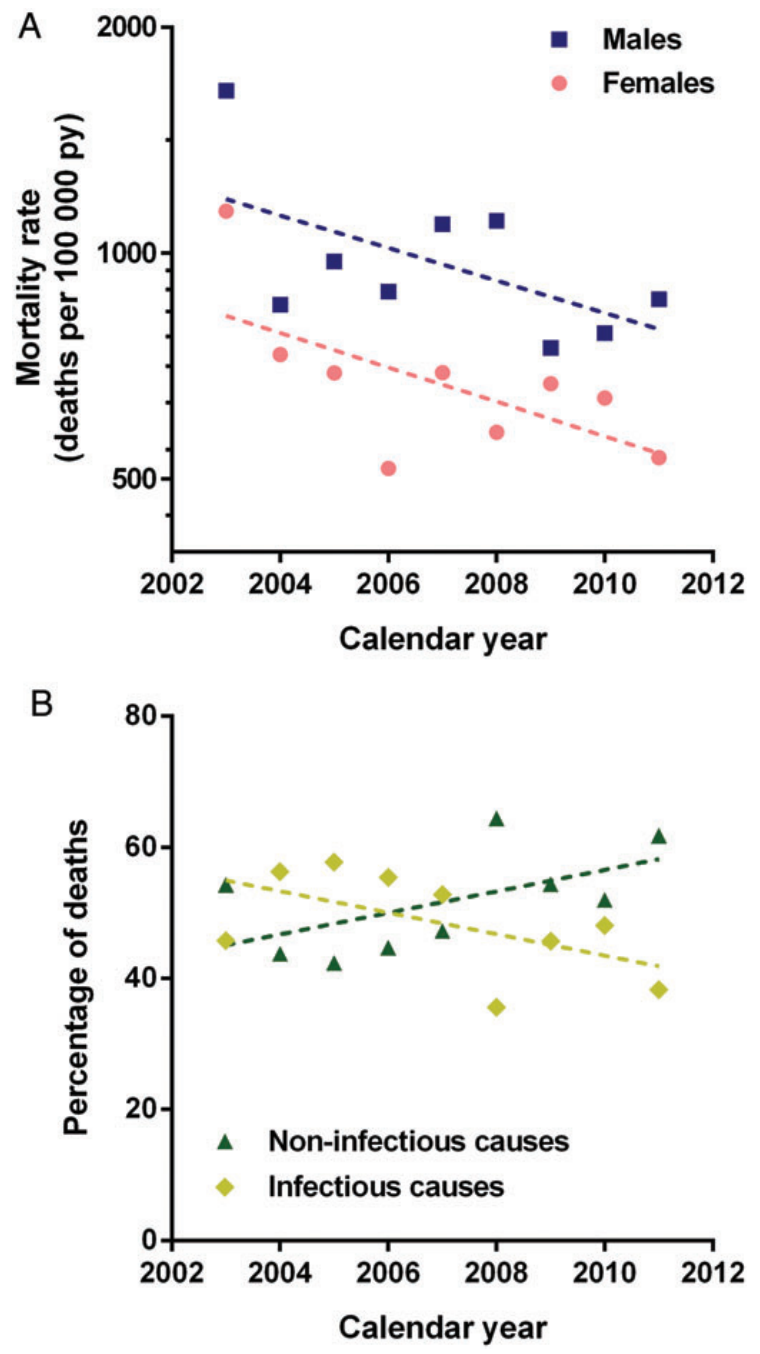

Figure 3. Decline in mortality (2002 to 2011). In (A) age-standardised sex-specific mortality rates per 100000 person-years (py) over calendar years are shown. In (B) the relative causes of death, classified as infectious or non-infectious, over calendar years as determined by verbal autopsy are shown.

Different models have been proposed to describe the declines in mortality and fertility during the various stages of the epidemiologic transition. ${ }^{1,2}$ The validity of these theories depend on the time and place of a transition. ${ }^{1,6,7}$ The transition in developing countries, as described by the protracted transition model, is expected to differ in two ways from the classical transition, as has been experienced by industrialised countries. First, while a decline in mortality is classically regarded as a prerequisite and precursor of a decline in fertility, these stages are not sequential but overlap in developing countries. Second, the classical transition is driven mainly by socioeconomic rather than medical factors, since a high socioeconomic status improves standards of living, health habits, hygiene and nutrition. ${ }^{1}$ However, in developing countries, the role of socioeconomic status and hygiene remains unclear.

In line with the protracted transition model, we observed concurrent declines in mortality and fertility and a coexistence of
Table 3. Determinants of the decline in mortality (2002 to 2011)

\begin{tabular}{llrr} 
& $\begin{array}{l}\text { Annual decline } \\
\text { in mortality rate }\end{array}$ & & p value \\
& $-5.0 \%$ & $(-7.0$ to -2.9$)$ & $<0.001$ \\
\hline $\begin{array}{l}\text { Overall } \\
\text { Age group }\end{array}$ & & & \\
$\quad$ 1-14 years & $-4.2 \%$ & $(-7.7$ to -0.5$)$ & 0.026 \\
15-64 years & $-6.6 \%$ & $(-9.8$ to -3.3$)$ & $<0.001$ \\
$>65$ years & $-3.9 \%$ & $(-7.4$ to -0.2$)$ & 0.038 \\
Sex & & & \\
$\quad$ Male & $-4.8 \%$ & $(-7.5$ to -2.1$)$ & 0.001 \\
$\quad$ Female & $-5.2 \%$ & $(-8.2$ to -2.1$)$ & 0.001 \\
Socioeconomic status & & & \\
$\quad$ Below average & $-5.3 \%$ & $(-8.4$ to -2.1$)$ & 0.001 \\
$\quad \begin{array}{l}\text { Above average } \\
\text { Water source }\end{array}$ & $-3.6 \%$ & $(-6.2$ to -0.8$)$ & 0.012 \\
$\quad \begin{array}{l}\text { Unimproved } \\
\text { Improved }\end{array}$ & $-6.5 \%$ & $(-10.7$ to -2.2$)$ & 0.004 \\
$\quad-4.4 \%$ & $(-6.7$ to -2.1$)$ & $<0.001$
\end{tabular}

The annual decline has been calculated as the relative change in the hazard ratio and is given with a $95 \%$ confidence interval $(95 \% \mathrm{CI})$. Differences in the annual declines in mortality rates between age groups, sexes, groups of socioeconomic status, and types of water source are non-significant.

infectious and non-infectious diseases, known as a double burden of disease. ${ }^{3,5,8}$ During the follow-up period, we did not observe the start of the transition in the research area and our conclusions are confined to the follow-up period. Therefore, we cannot make inferences on the start of the declines in mortality and fertility and their relative timing. Furthermore, we observed that male and female fertility trends converged during the period of follow-up. This finding could point to a decrease in the prevalence of polygamy, which would be in line with an ongoing epidemiologic transition.

It is tempting to hypothesise about possible elements that have contributed to the epidemiologic transition in rural Ghana. Previously, we have described socioeconomic status and water source as determinants of absolute mortality over age in our study population. Risk of mortality is increased for those with a low socioeconomic status and those who drink from unimproved water sources. ${ }^{9,10,25}$ Although socioeconomic status and water source determine survival, they did not relate to the declines of mortality and fertility during the epidemiologic transition. Possibly, these declines have started earlier in groups with a relatively high socioeconomic status or access to an improved water source, so that the absolute levels of mortality differ, but the declines in mortality do not differ.

Importantly, socioeconomic status and water source have likely been stable factors in the research population. This assumption is supported by the fact that the effects of socioeconomic status and water source on mortality did not differ between different periods of follow-up. It has been shown that the heritability of socioeconomic status in pre-transitional societies is substantial, especially when material wealth is of relatively more importance 


\section{F. M. Engelaer et al.}

Table 4. Determinants of the decline in fertility (2002 to 2011)

\begin{tabular}{|c|c|c|c|c|c|c|}
\hline & \multicolumn{3}{|c|}{ General fertility rate } & \multicolumn{3}{|l|}{ Child-adult ratio } \\
\hline & Annual decline & $95 \%$ CI & p value & Annual decline & $95 \%$ CI & $p$ value \\
\hline \multicolumn{7}{|l|}{ Women } \\
\hline Overall & $-12.7 \%$ & $(-16.9$ to -8.4$)$ & $<0.001$ & $-11.9 \%$ & $(-12.5$ to -11.2$)$ & $<0.001$ \\
\hline \multicolumn{7}{|c|}{ Socioeconomic status } \\
\hline Below average & $-13.9 \%$ & $(-20.0$ to -7.5$)$ & $<0.001$ & $-12.6 \%$ & $(-13.4$ to -11.8$)$ & $<0.001$ \\
\hline Above average & $-12.6 \%$ & $(-15.7$ to -9.4$)$ & $<0.001$ & $-11.8 \%$ & $(-12.4$ to -11.3$)$ & $<0.001$ \\
\hline \multicolumn{7}{|l|}{ Water source } \\
\hline Unimproved & $-11.0 \%$ & $(-16.8$ to -4.8$)$ & 0.001 & $-12.0 \%$ & $(-13.1$ to -11.1$)$ & $<0.001$ \\
\hline Improved & $-13.6 \%$ & $(-15.3$ to -9.7$)$ & $<0.001$ & $-12.1 \%$ & $(-12.6$ to -11.5$)$ & $<0.001$ \\
\hline \multicolumn{7}{|l|}{ Men } \\
\hline Overall & $-15.0 \%$ & $(-19.1$ to -10.8$)$ & $<0.001$ & $-14.0 \%$ & $(-14.8$ to -13.2$)$ & $<0.001$ \\
\hline \multicolumn{7}{|c|}{ Socioeconomic status } \\
\hline Below average & $-15.6 \%$ & $(-21.4$ to -9.4$)$ & $<0.001$ & $-14.4 \%$ & $(-15.3$ to -13.4$)$ & $<0.001$ \\
\hline Above average & $-15.3 \%$ & $(-15.3$ to -12.1$)$ & $<0.001$ & $-14.3 \%$ & $(-15.0$ to -13.7$)$ & $<0.001$ \\
\hline \multicolumn{7}{|l|}{ Water source } \\
\hline Unimproved & $-14.1 \%$ & $(-19.4$ to -8.3$)$ & $<0.001$ & $-14.9 \%$ & $(-15.9$ to -13.8$)$ & $<0.001$ \\
\hline Improved & $-15.7 \%$ & $(-19.4$ to -11.8$)$ & $<0.001$ & $-14.1 \%$ & $(-14.7$ to -13.4$)$ & $<0.001$ \\
\hline
\end{tabular}

The annual decline has been calculated as the relative change in the general fertility rate or the child-adult ratio and is given with a $95 \%$ confidence interval ( $95 \%$ CI). Differences in the annual declines in fertility rates between groups of socioeconomic status and types of water source are non-significant.

than embodied or relational kinds of wealth, as is true for agricultural societies such as in this research area. ${ }^{26-29}$ In our study population, socioeconomic status has been primarily determined by material household property that is passed from parents to children, such as cattle, vehicles and iron roofing. ${ }^{9,11,12}$ Migration has been related to rapid changes in socioeconomic status, ${ }^{30}$ but annual migration in this research area was low. In general, if socioeconomic status has changed for all groups in the research area, relative differences remain stable. Concerning water sources, households predominantly draw from the most nearby and easily accessible source. As improved water sources, boreholes have been constructed in the research area by western NGOs from the 1970 s onwards. ${ }^{10,18}$ Since then, new boreholes have scarcely been introduced. During our 9 years' presence in the research area, we only incidentally found a dysfunctional borehole. This is in line with our informal observation that the water infrastructure did not significantly change during this period. The use of boreholes as opposed to rivers and open wells is dependent mainly on their distances to the household. In line with this, we found no association between socioeconomic status and water source in relation to the annual declines in mortality and fertility. In another district close to our research area, it has been documented that there is almost no relation between water source and socioeconomic status. ${ }^{31}$

It is possible that socioeconomic status does not contribute to the epidemiologic transition in this study population due to the local economic system, where goods are directly exchanged for other goods or services, according to the barter system. For the transition to occur in such an economy, small-scale developments that raise the productivity of the agricultural sector and that facilitate the trade with other regions are more important, but are, at the same time, more difficult to record than material wealth. ${ }^{32}$ Examples of such investments are the provision of land development techniques, means of transportation and education. In our study population, these requisites have long remained deficient, but are slowly developing. ${ }^{9}$ There is little incentive to produce more food than is locally needed, since crops are low in value and cannot be easily exported outside the area.

It has been suggested that public health measures can be responsible for inducing transition in rural African countries. ${ }^{1,4,6,7,33-36}$ This could be true for our study population, where public health services have improved during the follow-up period. In 2003, a national health insurance was established in Ghana. Its national coverage rose from 18\% in 2006 to $62 \%$ in $2009 .{ }^{36}$ In our study population, its coverage rose from $4 \%$ in 2007 to $24 \%$ in 2011. People enrolled in this health insurance programme are more likely to seek formal medical care. ${ }^{34,36}$ Moreover, the coverage of immunisation has risen, thanks to vaccination programmes for diphtheria, tetanus, pertussis, measles, hepatitis B and polio. Furthermore, mass treatment of parasitic diseases has also taken place in our research area. ${ }^{15}$ Such public health measures have probably been of benefit to the population in general, regardless of socioeconomic status and water source.

The epidemiologic transition in rural areas has several important implications for society. The coexistence of both infectious and non-infectious diseases is a double burden for public health. 

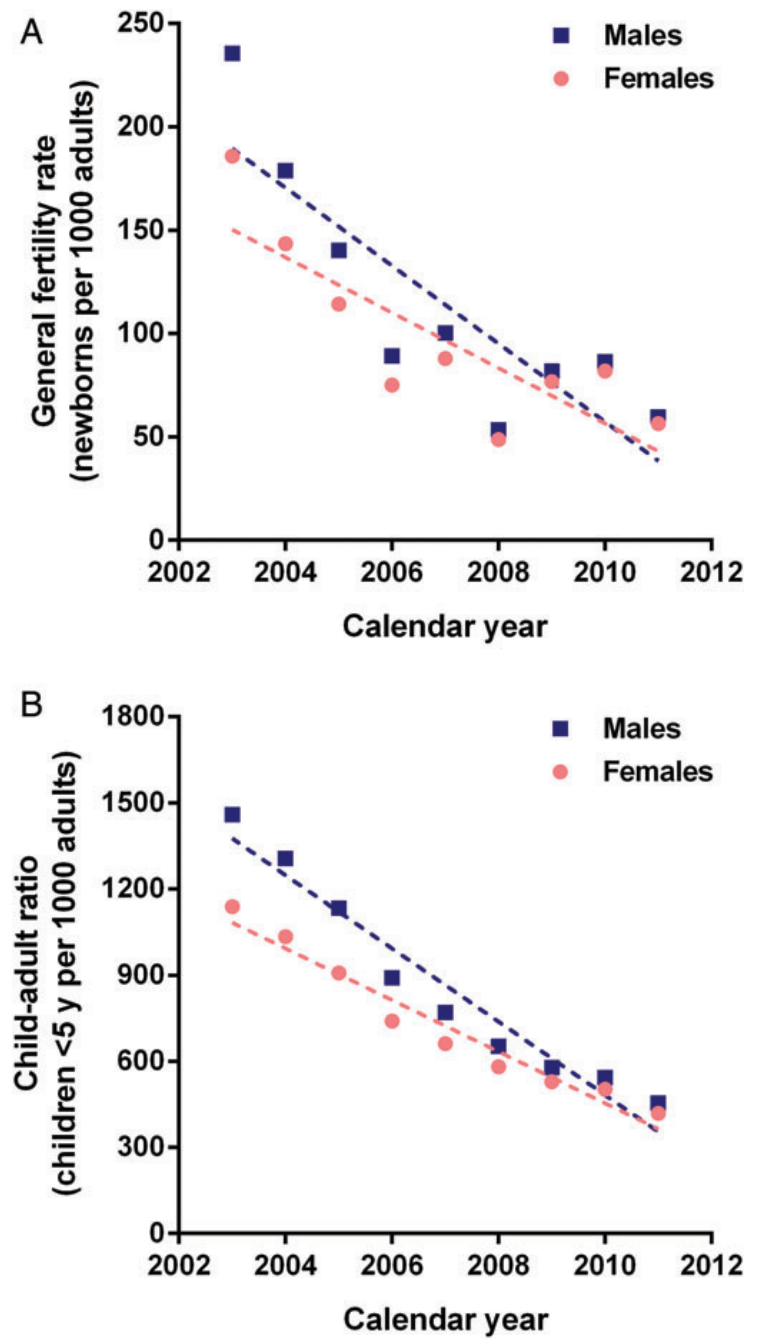

Figure 4. Decline in fertility (2002 to 2011). In (A) the general fertility rate as the number of births per 1000 men or women aged 19 to 44 over calendar years is shown, while in (B) the child-adult ratio as the number of children aged up to 5 years per 1000 men or women aged 19 to 49 over calendar years is shown.

We have previously stated that the absence of a sedentary lifestyle prevents the occurrence of cardiovascular disease in our study population. ${ }^{16}$ The progression of agricultural techniques and public health is likely to be accompanied by changes in lifestyle that strongly increase the risk of non-infectious diseases. ${ }^{2,37}$ Currently, the primary focus in rural areas is on cure, thereby neglecting prevention and care. ${ }^{2}$ Moreover, developing countries have limited resources to establish an effective response to the double burden of disease. ${ }^{38}$ More knowledge on the epidemiologic transition, its underlying determinants and the burden of disease can help rural African regions to develop more effective public health interventions.

As a strength of this study, follow-up was available for the entire population within the research area for a period of 9 years. Consequently, the mortality and fertility measures that we have documented represent true outcomes for this population. A limitation of this study is that it lacks reliable information on the survival of children aged less than 1 year. To estimate mortality in this age group, we conducted interviews in 2011 and registered whether children had been born and died between our field visits in 2010 and 2011. From this, we estimated the mortality rate to be 3313 per 100000 person-years. This number is similar to the mortality rate of this age group as reported for the entire Upper East region (3300 per 100000 births). ${ }^{12}$ Although we cannot draw conclusions about possible changes in mortality in this age group, this limitation does not undermine our conclusions for the other age groups. A further limitation is that we performed all verbal autopsy interviews in 2011 and the recall period varied from 0 to 9 years. However, the percentages of uncompleted verbal autopsies and of unspecified causes of death were distributed equally over the years. Next, declines in mortality and fertility were only related to socioeconomic status and water source, which were strongly related to mortality. ${ }^{9}, 10,25$ Other parameters were only measured in selected subgroups. ${ }^{10,} 16,17$ Finally, we lack certain information on women's fertility, such as changes in age at first birth, time between births, parity and cultural values related to fertility, which would have been valuable in evaluating the epidemiologic transition.

\section{Conclusions}

In rural Ghana, mortality and fertility decline in parallel during the epidemiologic transition. Socioeconomic status and water source do not play a role in these declines. Studying the epidemiologic transition in developing countries can direct specific public health interventions that can help to improve public health in these countries.

Authors' disclaimer: None of the funding organisations had any role in the design, analysis, interpretation or report of the study.

Authors' contributions: FME, JJEK, DVB, UKE and RGJW conceived the study and designed the study protocol; FME, JJEK, DVB and UKE carried out the data collection; FME and JJEK carried out the analyses; all authors carried out the interpretation of the data; FME and JJEK drafted the manuscript; DvB, UKE and RGJW critically revised the manuscript for intellectual content. All authors read and approved the final manuscript. RGJW is guarantor of the paper.

Acknowledgements: The authors are grateful for the dedicated work of the local assistance team during the data collection and for the assistance of physicians S.P. Gattu, F. Rosini, R.H. Medina Campos and A.G.C. Boef in the assessment of the verbal autopsies. The authors would also like to thank Dr B.J.A. Mertens, Prof. H. Putter (Department of Medical Statistics, Leiden University Medical Center) and Prof. F.J. Willekens (Netherlands Interdisciplinary Demographic Institute and Max Planck Institute for Demographic Research) for their assistance with the statistical methodology.

Funding: This work was supported by the Netherlands Foundation for Advancements of Tropical Research [WOTRO 93-467], the Netherlands Organization for Scientific Research [NOW 051-14-050], the EU funded Network of Excellence LifeSpan [FP6 036894], an unrestricted grant of the Board of the Leiden University Medical Center and Stichting Dioraphte.

Competing interests: None declared. 
Ethical approval: This study was approved by the Ethical Review Committee of the Ghana Health Service, the Medical Ethical Committee of the Leiden University Medical Center in Leiden, the Netherlands, and by the local chiefs and elders in the research area.

\section{References}

1 Omran AR. The epidemiologic transition. A theory of the epidemiology of population change. Milbank Mem Fund Q 1971;49:509-38.

2 Kahn K, Garenne ML, Collinson MA et al. Mortality trends in a new South Africa: hard to make a fresh start. Scand J Public Health Suppl 2007;69:26-34.

3 Yusuf S, Reddy S, Ounpuu S et al. Global burden of cardiovascular diseases: part I: general considerations, the epidemiologic transition, risk factors and impact of urbanization. Circulation 2001;104: 2746-53.

4 Rayco-Solon P, Moore SE, Fulford AJ et al. Fifty-year mortality trends in three rural African villages. Trop Med Int Health 2004;9:1151-60.

5 Agyei-Mensah S, de-Graft Aikins A. Transition and the double burden of disease in Accra, Ghana. J Urban Health 2010;87:879-97.

6 Cohen B. The emerging fertility transition in sub-Saharan Africa. World Dev 1998;26:1431-61.

7 Garenne M, Joseph V. The timing of the fertility transition in sub-Saharan Africa. World Dev 2002;30:1835-43.

8 Remais JV, Zeng G, Li G et al. Convergence of non-communicable and infectious diseases in low- and middle-income countries. Int $\mathrm{J}$ Epidemiol 2013;42:221-7.

9 Van Bodegom D, May L, Kuningas M et al. Socio-economic status by rapid appraisal is highly correlated to mortality in rural Africa. Trans R Soc Trop Med Hyg 2009;103:795-800.

10 Kuningas M, May L, Tamm R et al. Selection for genetic variation inducing pro-infammatory responses under adverse environmental conditions in a Ghanaian population. PLoS One 2009;4:e7795.

11 Ghana Statistical Service (GSS). Ghana Living Standards Survey: Report of the fifth round (GLSS 5). Accra: Ghana Statistical Service; 2008.

12 Ghana Statistical Service (GSS), Noguchi Memorial Institute for Medical Research and ORC Macro. Ghana Demographic and Health Survey 2003. Calverton, Maryland: Ghana Statistical Service, Noguchi Memorial Institute for Medical Research, and ORC Macro; 2004.

13 IFAD. Upper East Region Land Conservation and Smallholder Rehabilitation Project (LACOSREP): Phase II. Interim Evaluation. Report number 1757-GH. Accra: International Fund for Agricultural Development; 2006.

14 Ghana Health Service. Upper East Regional Health Directorate Annual Report 2009. Accra: Ghana Health Service; 2009.

15 Ziem JB, Olsen A, Magnussen P et al. Distribution and clustering of Oesophagostonum bifurcum and hookworm infections in northern Ghana. Parasitology 2006;132:525-34.

16 Koopman JJE, van Bodegom D, Jukema JW et al. Risk of cardiovascular disease in a rural African population with high infectious load: a population-based study. PLoS One 2012;7:e46855.

17 Boef AGC, May L, van Bodegom D et al. Parasitic infections and immune function: effect of helminth infections in a malaria endemic area. Immunobiology 2013;218:706-11.

18 Meij JJ, de Craen AJM, Agana J et al. Low-cost interventions accelerate epidemiologic transition in Upper East Ghana. Trans R Soc Trop Med Hyg 2009;103:173-8.

19 WHO/UNICEF Joint Monitoring Programme (JMP) for Water Supply and Sanitation. Types of drinking-water sources and sanitation. Geneva:
WHO/UNICEF Joint Monitoring Programme (JMP) for Water Supply and Sanitation; 2013. http://www.wssinfo.org/definitions-methods/ watsan-categories/ [accessed 3 January 2014].

20 Chandramohan D, Maude GH, Rodrigues LC et al. Verbal autopsies for adult deaths: their development and validation in a multi-center study. Trop Med Int Health 1998;3:436-46.

21 Kahn K, Tollman SM, Garenne M et al. Validation and application of verbal autopsies in a rural area of South Africa. Trop Med Int Health 2000;5:824-31.

22 Setel PW, Whiting DR, Hemed Y et al. Validity of verbal autopsy procedures for determining cause of death in Tanzania. Trop Med Int Health 2006;11:681-96.

23 Soleman N, Chandramaohan D, Shivuya K. Verbal autopsy: current practices and challenges. Bull World Health Org 2006;84:239-45.

24 WHO. Verbal autopsy standards: ascertaining and attributing cause of death. Geneva: World Health Organization; 2007.

25 Van Bodegom D, Rozing MP, May L et al. Socioeconomic status determines sex-dependent survival of human offspring. Evol Med Public Health 2013;1:37-45.

26 Borgerhoff-Mulder M, Bowles S, Hertz Tet al. Intergenerational wealth transmission and the dynamics of inequality in small-scale societies. Science 2009;326:682-8.

27 Bowles S, Smith EA, Borgerhoff-Mulder M. The emergence and persistence of inequality in premodern societies: introduction to the special section. Curr Anthropol 2010;51:7-17.

28 Borgerhoff-Mulder M, Fazzio I, Irons W et al. Pastoralism and wealth inequality: revisiting an old question. Curr Anthropol 2010;51:35-48.

29 Shenk MK, Boergerhoff-Mulder M, Beise J et al. Intergenerational wealth transmission among agriculturalists: foundations of agrarian inequality. Curr Anthropol 2010;51:65-83.

30 Beegle K, De Weerdt J, Dercon S. Migration and economic mobility in Tanzania: evidence from a tracking survey. Rev Econ Stat 2011;93:1010-33.

31 Shier RP, Dollimore N, Ross DA et al. Drinking water sources, mortality and diarrhoea morbidity among young children in northern Ghana. Trop Med Int Health 1996;1:334-41.

32 Tiffen M. Transition in sub-Saharan Africa: Agriculture, urbanization and income growth. World Dev 2003;31:1343-66.

33 Arevshatian L, Clements C, Lwanga $S$ et al. An evaluation of infant immunization in Africa: is a transformation in progress? Bull World Health Organ 2007;85:449-57.

34 Bawah AA, Phillips JF, Adjuik M et al. The impact of immunization on the association between poverty and child survival: evidence from Kassena- Nankana District of northern Ghana. Scand J Public Health 2010;38:95-103.

35 Rutherford ME, Mulholland K, Hill PC. How access to health care relates to under-five mortality in sub-Saharan Africa: systematic review. Trop Med Int Health 2010;15:508-19.

36 Blanchet NJ, Fink G, Osei-Akoto I. The effect of Ghana's National Health Insurance Scheme on health care utilisation. Ghana Med J 2012;46:76-84.

37 Teo K, Chow CK, Vaz M et al. The Prospective Urban Rural Epidemiology (PURE) study: examining the impact of societal influences on chronic noncommunicable diseases in low-, middle-, and high-income countries. Am Heart J 2009;158:1-7.

38 Maher D, Sekajugo J. Research on health transition in Africa: time for action. Health Res Policy Syst 2011;9:5. 